\title{
Pressure-Flow Studies in Man: Effect of Atrial Systole on Ventricular Function in Mitral Stenosis
}

\author{
M. Eugene Kendall, Abe Walston II, Frederick R. Cobb, and \\ Joseph C. GreENFIELd, JR. \\ From the Department of Medicine, Division of Cardiology, The Veterans \\ Administration Hospital, Durham 27705 and Duke University Medical Center, \\ Durham, North Carolina 27706
}

\begin{abstract}
A B S T R A C T The effect of atrial contraction on left ventricular function in six patients with varying degrees of mitral stenosis was determined by utilizing the pressure gradient technique to measure instantaneous aortic blood flow and pressure. Aortic flow was measured as ventricular rate was controlled by right ventricular pacing to create $\mathrm{A}-\mathrm{V}$ (atrioventricular) dissociation at varying rates ( $90-150$ beats $/ \mathrm{min})$. At each heart rate, beats with preceding $\mathrm{P}$ waves, effective atrial systole, were grouped according to the duration of the P-R interval. Beats without $P$ waves served as controls. There was always a significant increase in stroke volume, created by effective atrial systole, but the P-R interval at which it took place was different for each patient. There was no difference in the stroke volume for beats preceded by $P$ waves having a $P-R$ interval within the range of 0.05 $0.20 \mathrm{sec}$. These beats were grouped for each patient, subjected to regression analysis, and compared to control beats. The absolute and percent change created by effective atrial systole was inversely proportional to the severity of the disease as determined by mitral valve orifice size.
\end{abstract}

Effective atrial systole plays less of a role in augmenting left ventricular function in patients with mitral stenosis than in patients with normal valves.

\section{INTRODUCTION}

The effect of atrial systole on left ventricular function in patients with rheumatic mitral stenosis has been of interest to clinical investigators for several years. Carleton and Graettinger reported that atrial systole augmented

Dr. Greenfield is the recipient of Career Development Award (1-K3-HE-28,112) from the U. S. Public Health Service.

Received for publication 8 June 1971 and in revised form 10 August 1971. cardiac output by approximately $20 \%$ in patients without valvular disease, but made no significant hemodynamic contribution in the presence of mitral stenosis (1). On the other hand, Heidenreich, Thompson, Shaver, and Leonard reported a significant increase in diastolic flow and corresponding augmentation in left ventricular performance with effective atrial systole when compared to ineffective atrial systole (2). The major technical problems in resolving this question have been the inability to establish a realistic animal model or to measure left ventricular stroke volume on a beat-to-beat basis in patients with mitral stenosis. However, phasic aortic flow can be measured in man with the pressure gradient technique (3). The present study was undertaken to delineate the influence of a propertly timed atrial contraction on left ventricular function in patients with pure mitral stenosis.

\section{METHODS}

Five male patients and one female patient ranging in age from 22 to $58 \mathrm{yr}$, were studied following admission to the Durham Veterans Administration Hospital. All exhibited the auscultatory changes of pure mitral stenosis and were in normal sinus rhythm. Five of the six had electrocardiographic and X-ray findings of significant mitral stenosis. The clinical data describing these patients is given in Table $I$.

After informed consent was obtained, right- and left-sided cardiac catheterizations were performed using standard techniques. Left atrial pressure was recorded through a No. 2.5 Brockenbrough transeptal catheter ${ }^{1}$ to obtain the mitral gradient. Mitral valve orifice sizes, using the Gorlin formula, were calculated. The absence of either mitral and/or aortic regurgitation was ruled out with visualization of the left ventricle and aortic root after the injection of either Hypaque $76 \%{ }^{2}$ or Renografin $76 \% .^{3}$ Three of the five male patients

\footnotetext{
${ }^{1}$ United States Catheter \& Instrument Corp., Glens Falls, N. Y.

${ }^{2}$ Winthrop Laboratories, Division of Sterling Drug, Inc., New York.

${ }^{3}$ E. R. Squibb \& Sons, Inc., New York.
} 


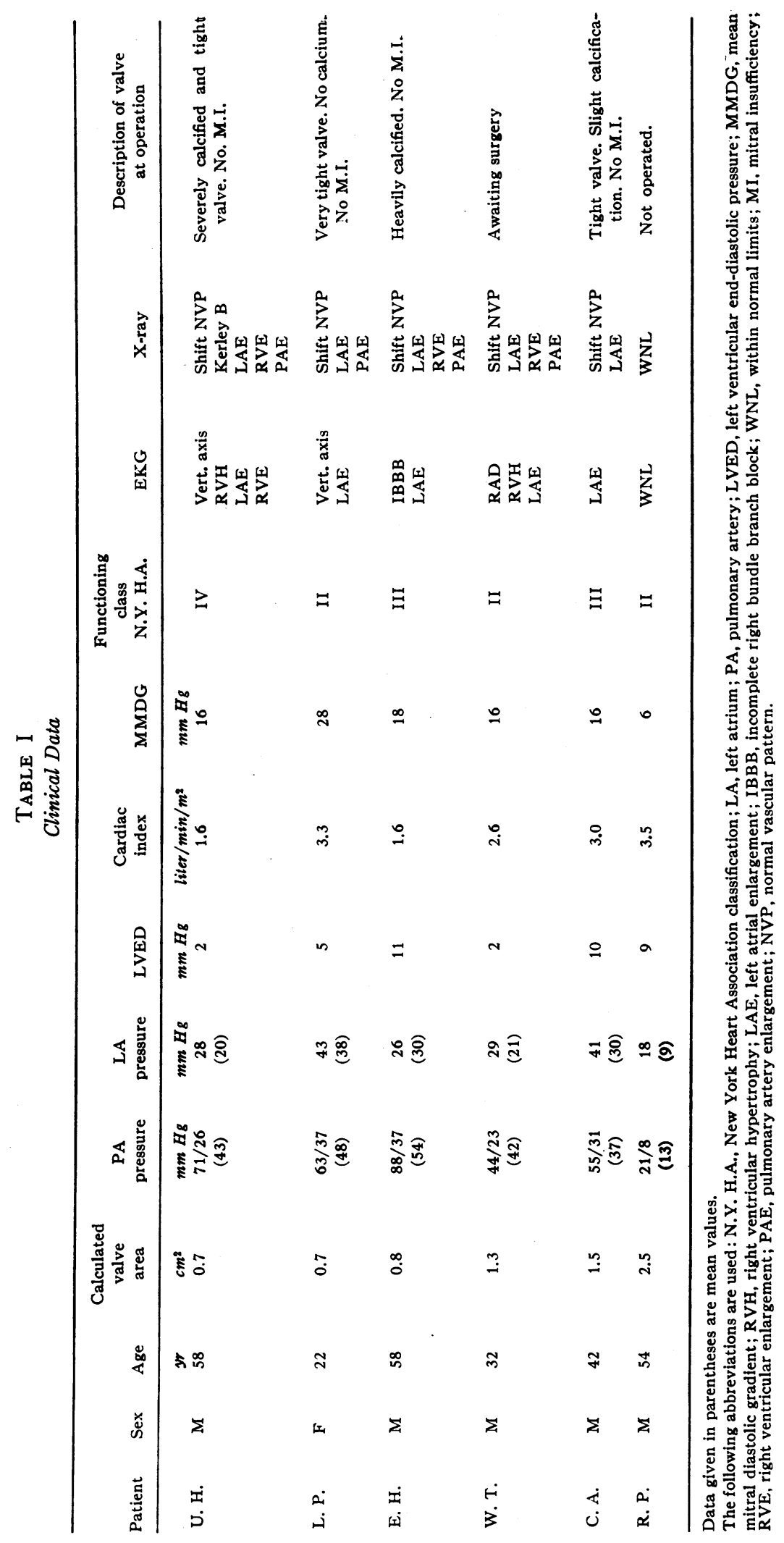

M. E. Kendall, A. Walston II, F. R. Cobb, and J. C. Greenfield, Jr. 

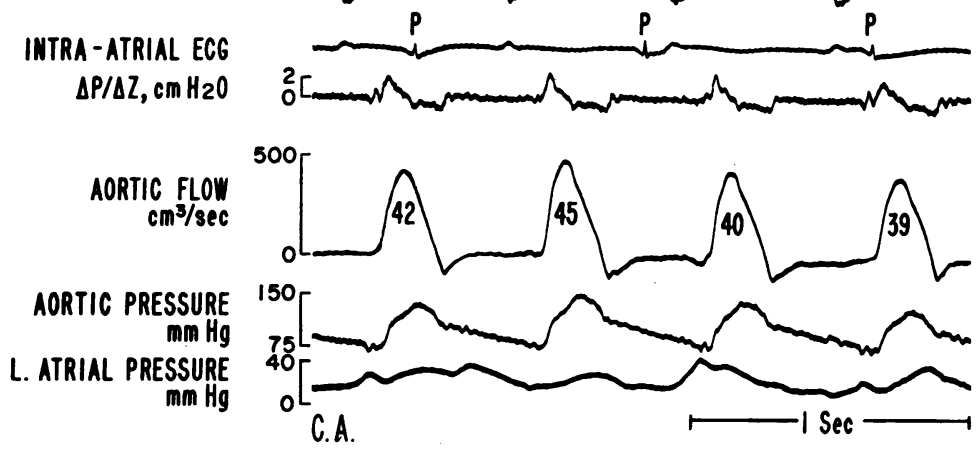

FIGURE 1 Pressure and flow recordings during ventricular pacing in patient C. A. with mitral stenosis at a rate of 120 beats/min. Surface ECG, intra-atrial ECG, pressure difference $(\Delta \mathrm{p} / \Delta \mathrm{z})$, aortic blood flow, aortic pressure, and left atrial pressure are displayed from the top down. Stroke volume in $\mathrm{cm}^{3}$ is listed for each beat under the flow recording. The minor change in systolic blood pressure and stroke volume can be seen with the variation in P-R interval.

had selective coronary arteriography using the Judkins technique and no significant lesions were visualized.

At the conclusion of the standard cardiac catheterization, a specially designed 6.5 French double lumen catheter, ${ }^{4}$ having lateral pressure taps $4 \mathrm{~cm}$ apart, was placed percutaneously into the femoral artery and advanced to the ascending aorta. The lateral pressures were accurately measured with a transducer-amplifier system. The pressure differences obtained with an analog computer ${ }^{5}$ were used to solve the proper equations for phasic blood flow (3). Ascending aortic pressure was simultaneously measured directly from one lumen of the catheter. A standard electrocardiogram and intra-atrial electrocardiogram, using a No. 7 Zucker bipolar pacing catheter, ${ }^{6}$ were recorded. A No. 5 bipolar pacing catheter $^{6}$ was placed at the apex of the right ventricle and connected to an external pulse generator ${ }^{7}$ in order to create complete $\mathrm{A}-\mathrm{V}^{\mathbf{8}}$ dissociation. Each patient was paced at the lowest rate at which ventricular capture took place without atrial competition and in increments of 10 beats per min to a maximal rate of approximately 150 beats per min. Each pacing rate was maintained for a minimum of $3 \mathrm{~min}$. All data were recorded on an optical recorder ${ }^{\theta}$ at a paper speed of $100 \mathrm{~mm} / \mathrm{sec}$ and on FM analog magnetic tape. ${ }^{10}$ The measurement of flow was not associated with any difficulties and the only inconvenience to the patient was the prolongation of the catheterization by approximately $30 \mathrm{~min}$.

Phasic blood flow was measured in the ascending aorta by the pressure gradient technique (3). This method is based on the solution of the Navier-Stokes equation of fluid motion, which relates the axial pressure gradient to the flow (4). The

"United States Catheter \& Instrument Corp., Glens Falls, N. Y.

${ }^{5}$ Model 3400 Analog Computer, Systron-Donner Corp., Concord, Calif.

${ }^{\circ}$ United States Catheter and Instrument Corp., Glens Falls, N. Y.

${ }^{7}$ Model 5800, Medtronic, Inc., Minneapolis, Minn.

${ }^{3}$ Abbreviations used in this paper: A-V, atrioventricular; EKG, electrocardiogram.

- Model 4568B, Hewlett-Packard Co., Palo Alto, Calif.

${ }^{10}$ Model 3955. Hewlett-Packard Co., Palo Alto, Calif. specific technique has been described in detail elsewhere ( 3 ) and the validity demonstrated in a flow generator (3), in dog aorta (5), and in man $(6,7)$.

Stroke volume was obtained by the planimetric integration of the area under each flow curve. Zero flow was assumed to be present at the end of diastole. Stroke work was computed as the product of the mean systolic blood pressure and stroke volume. For each beat analyzed the presence or absence of a $P$ wave was determined from the intra-atrial EKG. The P-R interval was defined as the time from the beginning of the $P$ wave to the pacing artifact. A total of approximately 800 heart beats were analyzed. Linear regression analysis and a Student $t$ test were used to evaluate the results of all computations, and plotting of data was carried out on a digital computer. ${ }^{11}$

\section{RESULTS}

A typical recording obtained in patient C. A. is shown in Fig. 1. Note that the stroke volume, listed under each flow curve, varies very little, regardless of P-R interval. In Table II, stroke volumes obtained at representative heart rates for each patient are listed as the mean and standard error of the mean. The standard error is not shown where there were fewer than three observations in a particular group. A P-R interval of zero indicates that no $\mathrm{P}$ wave occurred during the preceding diastole and will be referred to as control beats. In columns four through nine, data obtained at each designated P-R interval are listed. Statistical comparisons were performed in each patient to test for differences in stroke volume at different $P-R$ intervals, but no comparisons were made between patients. Since the stroke work was found to vary in exactly the same manner as the stroke volume, it is not listed.

${ }^{11}$ Model 1130, International Business Machines Corp., Armonk, N. Y. 
TABle II

The Effect of Atrial Systole on Ventricular Stroke Volume in Mitral Stenosis

\begin{tabular}{|c|c|c|c|c|c|c|c|c|c|}
\hline \multirow[b]{2}{*}{ Patient } & \multirow[b]{2}{*}{ Heart rate } & \multicolumn{8}{|c|}{ P-R interval, sec } \\
\hline & & $\begin{array}{c}0 \\
\text { sv }\end{array}$ & $\begin{array}{c}0.05-0.10 \\
\text { SV }\end{array}$ & $\begin{array}{c}0.11-0.15 \\
\text { SV }\end{array}$ & $\begin{array}{c}0.16-0.20 \\
\text { SV }\end{array}$ & $\begin{array}{c}0.21-0.30 \\
\text { SV }\end{array}$ & $\begin{array}{c}0.31-0.40 \\
\text { SV }\end{array}$ & $\begin{array}{c}0.41-0.50 \\
\text { SV }\end{array}$ & $\begin{array}{c}0.51-0.60 \\
\text { SV }\end{array}$ \\
\hline \multirow{4}{*}{ U. H. } & beats/min & \multicolumn{8}{|c|}{$\mathrm{cm}^{2}$} \\
\hline & 90 & $34 \pm 2$ & - & 35 & 38 & $40 \pm 1^{*}$ & $37 \pm 1$ & $36 \pm 1$ & - \\
\hline & 110 & $27 \pm 2$ & 34 & - & $34 \pm 1 *$ & $36 \pm 2 *$ & $36 \pm 1 *$ & - & - \\
\hline & 130 & $24 \pm 1$ & 38 & 33 & $36 \pm 2 *$ & $34 \pm 3^{*}$ & 二 & - & - \\
\hline L. P. & 150 & $19 \pm 1$ & $23 \pm 1$ & $27 \pm 1^{*}$ & $20 \pm 1$ & $21 \pm 1$ & 一 & - & - \\
\hline \multirow[t]{3}{*}{ E. H. } & 100 & $32 \pm 1$ & 35 & $37 \pm 1^{*}$ & $37 \pm 1^{*}$ & 37 & $35 \pm 3$ & 31 & - \\
\hline & 125 & $24 \pm 1$ & $30 \pm 2 *$ & 29 & 32 & $28 \pm 1$ & 工 & - & - \\
\hline & 146 & $19 \pm 1$ & 20 & 21 & $25 \pm 1^{*}$ & $20 \pm 1$ & - & - & - \\
\hline \multirow[t]{3}{*}{ w. T. } & 90 & $32 \pm 1$ & - & - & - & $38 \pm 1^{*}$ & $40 \pm 1^{*}$ & $36 \pm 1$ & $36 \pm 1$ \\
\hline & 115 & $27 \pm 1$ & 36 & 37 & $36 \pm 2^{*}$ & $33 \pm 2^{*}$ & 32 & 39 & - \\
\hline & 150 & $27 \pm 1$ & 37 & $36 \pm 2^{*}$ & $30 \pm 2$ & 23 & - & - & - \\
\hline \multirow[t]{3}{*}{ C. A. } & 120 & $34 \pm 4$ & 40 & - & - & 47 & $39 \pm 4$ & - & - \\
\hline & 136 & $32 \pm 1$ & $34 \pm 4$ & 40 & $37 \pm 1^{*}$ & $44 \pm 2 *$ & $37 \pm 2 *$ & - & - \\
\hline & 154 & $21 \pm 1$ & 23 & $34 \pm 3^{*}$ & $37 \pm 4^{*}$ & $38 \pm 2 *$ & $27 \pm 2 *$ & - & - \\
\hline \multirow[t]{3}{*}{ R. P. } & 88 & $37 \pm 1$ & $49 \pm 2 *$ & 59 & $53 \pm 3^{*}$ & 一 & - & - & - \\
\hline & 115 & $34 \pm 1$ & $47 \pm 1^{*}$ & $47 \pm 1^{*}$ & $41 \pm 1$ & - & - & - & - \\
\hline & 150 & $23 \pm 1$ & $41 \pm 3^{*}$ & 40 & 38 & 31 & - & - & - \\
\hline
\end{tabular}

In each column is listed the mean and standard error of the mean for stroke volume (SV) in $\mathrm{cm}^{\mathrm{s}}$ for each heart rate. If there were fewer than three ohservations in a group, only the mean value is given.

* Stroke volume at this particular P-R interval is statistically different from control at the same heart rate $(P<0.01)$.

In every patient the stroke volume of control beats decreased significantly when the rate was increased $(P<0.01)$. Data for patient L. P. are listed only at one heart rate (150 beats per min) since A-V dissociation could not be achieved below this rate. The presence of a preceding $\mathrm{P}$ wave always resulted in a significant increase in stroke volume over control beats $(P<0.01)$, but the $P-R$ interval at which the increase takes place is different for each patient. Although the presence of a $P$ wave resulted in a significant increase in stroke volume over control, there was no significant difference detected in the stroke volume of beats preceded by a $P$ wave with a $P-R$ interval in the range of $0.05-0.20 \mathrm{sec}$ $(P>0.05)$. Thus, data from these beats were combined and subjected to regression analysis. Regression lines for beats with a preceding $P$ wave, $P-R$ interval $0.05-0.20 \mathrm{sec}$, and control beats, no preceding $P$ waves, were calculated for each patient. These lines are seen in Fig. 2. C. S. (panel $A$ ) represents a patient with a normal mitral valve studied previously in this laboratory (8). In this patient the regression lines are parallel but their intercepts are different. There is an absolute increase in stroke volume of approximately $20 \mathrm{~mm}^{3}$ in beats with effective atrial systole over those of control beats at the highest and lowest rate. This represents a $24 \%$ increase in stroke volume at a rate of 58 beats per min and a $40 \%$ increase at the rate of 126 beats per min.
The slopes of the regression lines for patient R. P., with mild mitral valve disease (panel $B$ ), are not significantly different but the intercepts are. At a rate of 79 beats per min the lack of effective atrial systole decreased stroke volume in this patient $20 \%$, and $39 \%$, at a rate of 150 beats per min, while the absolute changes were $11 \mathrm{~cm}^{3}$ and $17 \mathrm{~cm}^{3}$ at the respective rates. C. A., with moderate mitral valve disease (panel $C$ ), had significantly different slopes and intercepts with a $2 \mathrm{~cm}^{3}(5 \%)$ difference in stroke volume at the lowest rate and a $12 \mathrm{~cm}^{3}(34 \%)$ at the highest rate. W. T., with moderate valvular disease (panel $D$ ), had an absolute increase of $5 \mathrm{~cm}^{3}$ at 90 beats per min and $7 \mathrm{~cm}^{3}$ at 150 beats per min,, which represents a $13 \%$ and $27 \%$ change over control values at the respective rates. $\mathrm{E}$. $\mathrm{H}$., with moderately severe disease (panel $E$ ), had a $5 \mathrm{~cm}^{8}(11 \%)$ increase in stroke volume at 100 beats per min and a $3 \mathrm{~cm}^{3}(16 \%)$ increase at 150 beats per min with effective atrial systole when compared to control beats. U. H., with severe mitral stenosis (panel $D$ ), had an increase in stroke volume of $4 \mathrm{~cm}^{3}(8 \%)$ at the lowest rate and $11 \mathrm{~cm}^{3}(20 \%)$ at a rate of 130 beats per min. The slope was different but the intercepts were not.

Fig. 3 shows the change in stroke volume following an effective atrial contraction as a per cent of the control stroke volume in seven patients with normal mitral valves previously studied in this laboratory 
(8) (open circles) and five patients with pure mitral stenosis (closed circles) at the lowest and highest pacing rates (triangles). At the highest paced rate the normal patients increased stroke volume from 40 to $150 \%$ whereas the patients with mitral stenosis changed from 10 to $40 \%$ with an effective atrial systole. It should be noted that the patient with the $40 \%$ change was R. P. who had very mild mitral stenosis. The maximum changes in the patients with severe mitral stenosis was $25 \%$.

Determination of left atrial pressure revealed no significant increase in the $\mathrm{V}$ wave of the control beats, indicating that mitral insufficiency did not occur in these beats. The left atrial A wave became larger as it approached ventricular systole and was at its largest when contracting against a closed mitral valve.

Although the average peak systolic blood pressure appeared to be slightly higher in effective atrial systole when compared to control beats (range 0-20\%), no statistically significant difference could be shown except in patient $R$. P., with very mild mitral disease, where a $20 \%$ difference was found $(P<0.01)$. Pulse pressure reacted in a similar fashion.

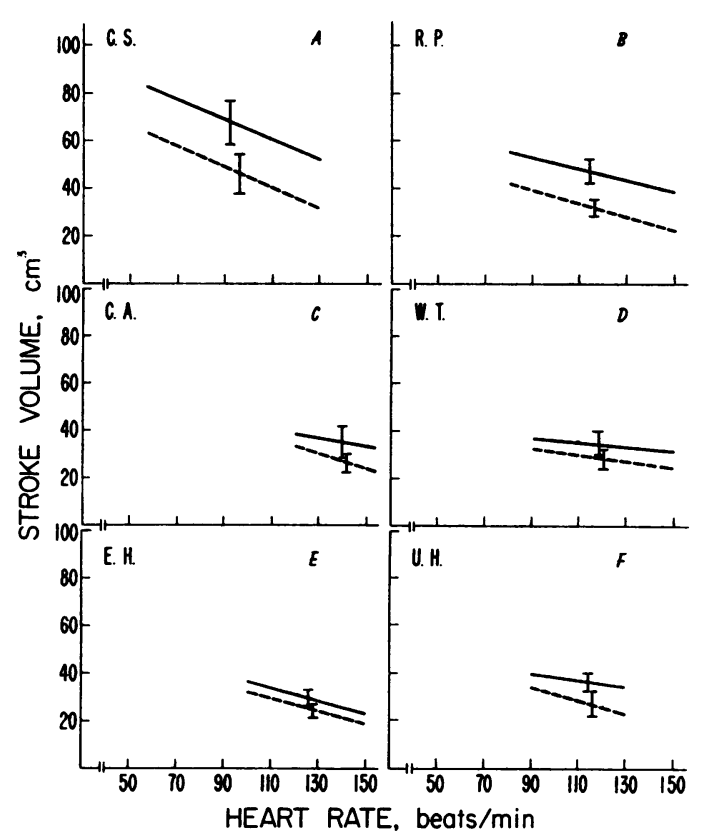

Figure 2 Regression lines calculated for stroke volume (on the ordinate) as function of heart rate (on the abscissa) are shown for a patient without mitral valve disease (C. S.) and five patients (R. P., C. A., W. T., E. H., and U. H.) with mitral stenosis in order of the severity of their disease. The regression lines for beats without a preceding $P$ wave are shown as broken lines, and for beats following a $P$ wave as solid lines. The standard error of estimate for each line is given by the crossed bar (see text).

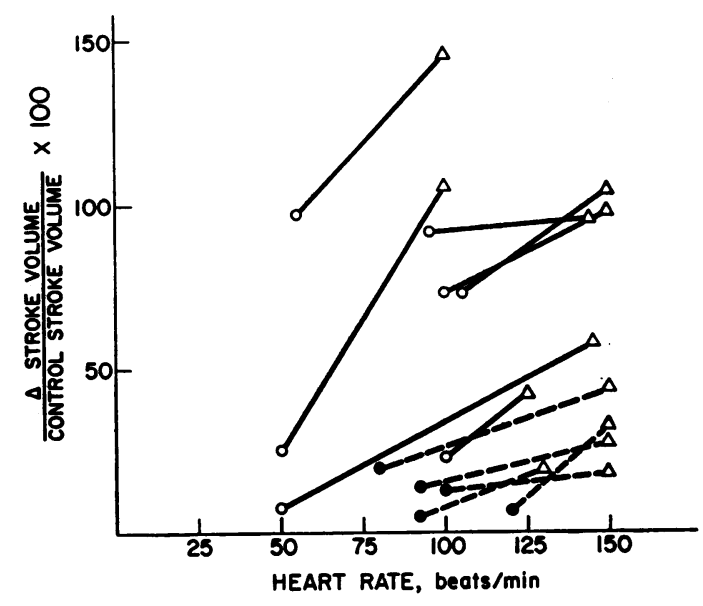

FIGURE 3 The change in stroke volume as a per cent of the control stroke volume is given for seven patients without mitral valve disease $(O)$ and five with mitral stenosis (0) at the lowest and highest $(\Delta)$ heart rates. There is a variation among the normals but all exceed the changes seen in those with mitral stenosis.

\section{DISCUSSION}

The importance of atrial contribution to left ventricular function in the experimental animal $(9,10)$ and in normal humans (8) has been thoroughly evaluated, but little has been written about its significance in rheumatic heart disease and, in particular, pure mitral stenosis. Carleton and Graettinger, using synchronous and sequential atrial pacing, reported effective atrial systole to improve normal human's left ventricular output by $20 \%$ but found no effect on individuals with mitral stenosis (1). These results were, unfortunately, subject to all the homeostatic mechanisms that take place in cardiac output regulation during the steady state and are not comparable to the data presented in our study. Using the stenotic mitral valve as a flowmeter and calculating the diastolic flow with the Gorlin formula, Heidenreich et al. (2) reported a $24 \%$ increase in diastolic flow. In addition, their studies revealed a $24 \%$ increase in mean peak left ventricular systolic pressure, and a $13 \%$ increase in mean left ventricular ejection time when comparing effective and ineffective atrial systole. They subsequently showed a $19 \%$ increase in diastolic flow and an $11 \%$ increase in left ventricular ejection time in a similar study except that isorhythmic dissociation was substituted by sequential and synchronous A-V pacing (11). We found comparable data for patient $R$. P. with very mild disease. He showed a $20 \%$ increase in average peak systolic pressure and a $20 \%$ increase in stroke volume when comparing effective and ineffective atrial systole. As heart rate was increased, stroke volume was augmented by $40 \%$ with effective atrial systole. However, in the pa- 
tients with more severe stenosis of the valve, the increase in average peak systolic blood pressure, stroke volume, and mean pulse pressure, created by effective atrial systole, became much smaller. Heidenreich and coworkers $(2,11)$ grouped their patients and averaged the data. Thus, their results might have been skewed by the fact that the predominance of their patients had relatively mild mitral stenosis.

None of these investigators $(1,2,11)$ varied heart rate in making their determinations. Mitchell, Gupta, and Payne's work in the dog (12) and reports from this laboratory (8) in patients without mitral valve disease show the absolute increase in stroke volume created by effective atrial systole to be independent of heart rate. In the patient with mild mitral stenosis, we found similar results. However, as the severity of the disease increased, as manifest by decrease in calculated mitral valve size, the absolute change in stroke volume created by effective atrial systole was markedly diminished. The absolute change in stroke volume became larger in two patients as the heart rate was increased, indicating that atrial contraction might be more important in maintaining ventricular filling at higher heart rates.

The fact that the stroke volume of control beats was smaller might be explained as evidence for the presence of mitral insufficiency occurring because of the absence of atrial contraction. Ruskin, McHale, Harley, and Greenfield (8) did phonocardiograms on their patients which failed to reveal mitral insufficiency or other cardiac murmurs. In our patients there were no significant changes in left atrial $\mathrm{V}$ wave pressure to suggest an increase in mitral insufficiency during the control beats. These data would support the opinion of Braunwald, Rockoff, Oldham, and Ross (13) in humans and Williams, O'Donovan, Cronin, and Wood's work in dogs (14) that a properly timed atrial contraction is not always essential for mitral valve closure.

Ultimately, three factors determine the stroke volume in mitral stenosis: (a) the functional capacity of the atrium, $(b)$ compliance of the left ventricle, and (c) impedance of blood flow at the stenotic mitral valve site. None of our patients had been in atrial fibrillation and when the atrium contracted against a closed valve, good pressure responses were recorded. Thus, from this data, the inability of the atrium to act as an effective pump did not seem to be a factor. All patients studied had normal left ventricular end-diastolic pressures at rest but none were measured with exercise or during pacing. Of the four patients operated, all but one had excellent clinical results subsequent to relieving the obstruction of the mitral valve. $U$. $H$. had only mild improvement. One might postulate that poor ventricular compliance is the reason for the lack of dramatic improvement in this patient. This has been suggested by several investigators in the past (15-18). The most reasonable explanation for the markedly reduced effect of atrial systole in augmenting stroke volume in patients with severe mitral stenosis is the loss of energy secondary to marked turbulence of blood flowing across the deformed mitral valve. Thus, raising atrial pressure by atrial systole will not result in a meaningful increase in flow during diastole, since the energy will be dissipated at the valve.

The data for this study cannot be used to show that restoration of sinus rhythm in patients with atrial fibrillation will be ineffective. Aside from the considerations of prophyllaxis against embolism, normal sinus rhythm may augment ventricular function by maintaining a slower heart rate. In addition, the nonfibrillating atrium should be better able to provide the high diastolic pressure needed to maintain flow across the mitral valve.

\section{ACKNOWLEDGMENTS}

The authors gratefully acknowledge the technical assistance of Miss Judith C. Rembert, Mr. Philip A. McHale, Mrs. Katherine Smith, Mrs. Della Foster, Mr. Marvin Mickens, Mrs. Nobuko U, Mrs. Jessie McCray, and Mrs. Rosa B. Ethridge. The continued support of the Medical Illustration Service of the Durham Veterans Administration Hospital is appreciated.

This work was supported in part by National Institutes of Health Grant No. HE-09711 and Training Grant No. HE05736 from the U. S. Public Health Service.

\section{REFERENCES}

1. Carleton, R. A., and J. S. Graettinger. 1967. The hemodynamic role of the atria with and without mitral stenosis. Amer. J. Med. 42: 532.

2. Heidenreich, F. P., M. E. Thompson, J. A. Shaver, and J. J. Leonard. 1969. Left atrial transport in mitral stenosis. Circulation. 40: 545.

3. Greenfield, J. C., Jr. 1966. Pressure gradient technique. Methods Med. Res. 11: 83.

4. Fry, D. L. 1959. The measurement of pulsatile blood flow by the computed pressure gradient technique. IRE Trans. Med. Electron. 6: 259.

5. Greenfield, J. C., Jr., and D. L. Fry. 1965. Relationship between instantaneous aortic flow and the pressure gradient. Circ. Res. 17: 340.

6. Hernandez, R. R., J. C. Greenfield, Jr., and B. W. McCall. 1964. Pressure-flow studies in hypertrophic subaortic stenosis. J. Clin. Invest. 43: 401.

7. Harley, A., C. F. Starmer, and J. C. Greenfield, Jr. 1969. Pressure-flow studies in man: an evaluation of the duration of the phases of systole. J. Clin. Invest. 48: 895.

8. Ruskin, J., P. A. McHale, A. Harley, and J. C. Greenfield, Jr. 1970. Pressure-flow studies: effect of atrial systole on left ventricular function. J. Clin. Invest. 49: 472.

9. Skinner, M. S., Jr., J. H. Mitchell, A. G. Wallace, and S. J. Sarnoff. 1963. Hemodynamic effects of altering the timing of atrial systole. Amer. J. Physiol. 205: 499. 
10. Linden, R. J., and J. H. Mitchell. 1960. Relation between left ventricular diastolic pressure and myocardial segment length and observations on the contribution of atrial systole. Circ. Res. 8: 1092.

11. Heidenreich, F. P., J. A. Shaver, M. E. Thompson, and J. J. Leonard. 1970. Left atrial booster function in valvular heart disease. J. Clin. Invest. 49: 1605.

12. Mitchell, J. H., D. N. Gupta, and R. M. Payne. 1965. Influence of atrial systole on effective ventricular stroke volume. Circ. Res. $17: 11$.

13. Braunwald, E., S. D. Rockoff, H. N. Oldham, and J. Ross, Jr. 1966. Effective closure of the mitral valve without atrial systole. Circulation. 33: 404.

14. Williams, J. C. P., T. P. B. O'Donovan, L. Cronin, and E. H. Wood. 1967. Influence of sequence of atrial and ventricular systoles on closure of mitral valve. J. Appl. Physiol. 22: 786.

15. Grant, Robert P. 1953. Architectonics of the heart. Amer. Heart J. 46: 405.

16. Feigenbaum, H., R. W. Campbell, C. M. Wunsch, and E. F. Steinmetz. 1966. Evaluation of the left ventricle in patients with mitral stenosis. Circulation. 34: 462.

17. Harvey, R. M., M. I. Ferrer, P. Samet, R. A. Bader, M. E. Bader, A. Cournand, and D. W. Richards. 1955. Mechanical and myocardial factors in rheumatic heart disease with mitral stenosis. Circulation. 11: 531.

18. Kasalicky, J., J. Hurych, J. Widimsky, R. Dejdar, R. Metys, and V. Stanek. 1968. Left heart haemodynamics at rest and during exercise in patients with mitral stenosis. Brit. Heart J. 30: 188. 